\title{
Community Interpreting in mental health: research issues
}

\author{
Hanneke Bot \\ De Gelderse Roos, Phoenix department, Wolfheze, the Netherlands
}

The question this article tries to deal with is: how does mental health talk differ from dialogue in other public service areas? The contribution starts with a description of the organization of interpreting in health care and the level of professionalization of the field in the Netherlands, which is really not all that different from that in other western countries. Then a description and discussion of some major publications concerning interpreting in (mental) health care and their methodological backgrounds will be presented. However, only a few publications are based on a systematic investigation. Summarizing the findings from these research projects, we can conclude that the interpreter influences the content of the communication in several ways. Firstly, because of language pair dependent changes and, secondly, because of changes that are dependent on the interpreter: his ${ }^{l}$ (lack of) knowledge of the type of communication in hand; his (lack of) knowledge of the institutional setting in which the communication takes place and the specific linguistic characteristics of that type of talk; his (un)conscious personal ideas, values and norms which make him diverge from the original text. Finally, we will summarize where we stand as far as the knowledge about interpreting in mental health is concerned ${ }_{2}$ and the contribution closes with some proposals for further research.

\section{Interpreting services in the Netherlands}

In the Netherlands, the use of interpreters in health care has been laid down most clearly in the law concerning 'informed consent' ${ }^{2}$. This states that information has to be given to the patient in a language he can understand. In a number of other laws concerning the quality of health care, the necessity of adequate communication is also emphasized. Implicitly this means that interpreters have to be used in case a patient does not share a language with the healthcare provider.

In the beginning of 2006 the Dutch Ministry of Health sent a letter to all medical institutions asking for attention to communication problems with patients with limited Dutch proficiency. The existence of the Dutch Interpreter and Translation Centre was brought to their attention, including the fact that health providers can make use of the services of this centre at no immediate cost to the provider. The responsibility of the healthcare providers to communicate in a language the patient can understand was once again emphasized. Healthcare providers are responsible for the use of a professional interpreter, who has to be engaged by the health provider. This 
means that they should not rely on interpreters brought along by the patient, because they may not be impartial and may not have the necessary language and interpreting skills. In the same letter, it is also pointed out that health providers have the duty to train themselves in the skills necessary for the communication through an interpreter. Due to financial and economic restrictions, interpreting by telephone is encouraged.

The concept of 'professional interpreter' is used to distinguish such professionals from family members, bilingual hospital staff and other people who may serve as interpreters on a ad hoc basis. Professional interpreters interpret for a living, i.e. they are paid to do so, they have an independent status with regard to the people they interpret for and they have to respect a code of conduct, including a pledge of secrecy. This also means that any complaints concerning their professional behaviour will be dealt with in an organized fashion through an independent complaints committee. It implies that the users of interpreter services understand the professional status of the interpreter and do not ask interpreters to carry out tasks beyond their professional boundaries.

'Professional' also refers to a certain level of education and training. But "the criteria for deciding what or who is professional or not in interpreting are not always hard and fast" (Pöchhacker 2004: 23) and, moreover, these criteria may also be different in different institutional contexts. Professional education and training involve an organizational infrastructure as well. For example, the Dutch Ministry of Justice ${ }^{3}$ has recently started a register for interpreters. Interpreters now have to possess certain qualifications in order to be allowed to register and there is also a requirement for continuous professional development (CPD). In the near future, government services will be allowed to use only registered interpreters. In the period $1999-2005$, a specific committee ${ }^{4}$, set up by the Ministry of Justice and with subcommittees for each language pair, assessed the interpreters who were at that moment working in the subsidized circuit. This process has been evaluated and recommendations for the future about the way in which this assessment should be carried out have been made (B \& A Groep 2005). In the future, an independent quality institute will administer the register, organize assessment procedures and monitor interpreting issues in general. The qualifications interpreters should possess are generally defined as: integrity; professional attitude; language proficiency in Dutch and the foreign language; knowledge of the Netherlands and the foreign country.

Furthermore, there is a provision for certain languages ('exotic languages') for which there is no available expertise to assess language proficiency; interpreters in such languages can be registered without having passed the necessary tests.

Remarkably enough, a lot of attention is being paid to the assessment of interpreters but so far no attention is paid to the training of the service providers. In its communication to the healthcare institutions, the Ministry of Health has prescribed that health providers ought to train in the necessary skills to communicate with an interpreter. However, at present, such training does not exist ${ }^{5}$. 
Generally speaking one could say that the issues at stake in the Netherlands are really not very different from many other western countries. One important difference, however, is that interpreting services are heavily controlled by the government and are organized centrally. This implies that we do not have a system of in-house interpreters ${ }^{6}$. Interpreters are thus not part of a healthcare team - they move from one institute to another or work for different care providers via the telephone. The emphasis is on their task as translators, they are neither co-therapists nor culture brokers.

\section{Mental health dialogue versus other public service talk}

It is striking that the requirements for interpreters make no mention of knowledge of the specific situations in which they work. In my work I have found that interpreting in mental health is quite different from interpreting in other public service talk in several respects (Bot 2003; 2005), which I have grouped together on the basis of four factors: the controlling and monitoring power of the therapist, the skills and the attitude of the interpreter, and the (feeling of) security of the patient.

Therapists feel that they easily lose control over the dialogue when an interpreter is involved. This may not be different in interpreter-mediated talk in other disciplines: as the primary speakers do not immediately understand what is going on, they may feel dependent and out of control. However, the difference between other contexts and mental health care is that in mental health care the development of the relationship between the therapist and the patient is of prime importance. This relationship is necessary for the formation of a working alliance and is also used diagnostically.

The question then is: how does an interpreter fit into this relationship? How does the presence of the interpreter influence the psychotherapeutic concepts of transference, countertransference and resistance? Do therapists indeed pay attention to these phenomena with regard to the interpreter? And if they do, do they speculate about the way the interpreter deals with these phenomena based on their observations? Do they perhaps discuss them with the patient - through the interpreter? Do they also discuss them with the interpreter as a participant in his own right?

As far as the skills of the interpreter are concerned, it is evident that the interpreter should be fluent in both the source and the target languages. A point of attention, though, is the subject of talk. In the Netherlands interpreters are required to be able to interpret a concise narrative, spoken at normal speed and not lasting for more than two minutes. Mental health sessions normally deal with difficult issues: narratives loaded with shame, guilt, pain and sorrow. Patients do not usually talk about these things easily and when they do, they are often not able to do so concisely. Psychiatric patients may have hallucinations and talk about them, they may talk in a disjointed way or use words that do not 'exist'. Now how do interpreters deal with these problems? Do they give a description of or try to paraphrase the specific language use of the patient, or do they (try to) imitate it in their 
renditions? How does this influence the diagnostic process in psychiatry? As it is important for therapists to understand the way in which patients speak about themselves and their experiences - for example, does the patient talk about himself in the active or in the passive voice- one can posit that it is equally important for interpreters to retain these subtleties in their renditions. But do they?

The patient's words may be difficult to translate, but the same also applies to the therapist's words. Therapists are trained to formulate their interventions in a specific way, for example as a confrontation or as a reflection, and such differences are usually expressed by the use of specific grammatical constructions. Do interpreters retain these constructions or do they ignore such subtleties, maybe as a result of their lack of knowledge of their therapeutic importance? And if such changes are made, how does this affect the interaction in the session among the participants and the overall course of the therapy?

Another issue is the source of divergence in renditions. Besides the obvious factors such as the levels of difficulty of the original utterances and the language proficiency in both the interpreter's languages, there seems to be a complicating factor as far as interpreting in mental health is concerned. Yahyaoui (1988), for one, rejects the use of interpreters in mental health sessions altogether as he assumes the unconscious of the interpreter will loom large in his renditions. He assumes that this interferes with his translational activity: his psychology will be included in his renditions. Does this imply that interpreters need to have undergone training-therapy ${ }^{7}$ before they can work in mental health sessions? This issue comes close to the problem of vicarious traumatization, which is important for therapists working with seriously ill patients, but do we have any idea how this affects the interpreters?

The attitude of the interpreter is another point of concern. The official prescription demanding that the interpreter remain objective, neutral and non-judgemental may sometimes be difficult to achieve. It is not always easy to define where neutrality starts and 'stand-offishness' begins. My own research points to the importance of agreement between therapist and interpreter first about how to approach the patient; agreement between therapist and interpreter about both the role of the interpreter and the ability of the interpreter to be empathic (Bot 2003). These factors refer to the general attitude necessary to make the patient feel at ease and to enable the formation of a working alliance. Will interpreters automatically understand what is expected of them in this respect? Or do they need training to help them understand what kind of behaviour is acceptable; where they may divert from strict neutrality and how the boundaries of professional behaviour in mental health sessions are defined?

With respect to the patient's feeling of security, an empathic attitude on the part of both the therapist and the interpreter is important. A patient once told me how difficult it had been for him to see his therapist and his interpreter talking and laughing together before the sessions: he felt terribly left out and 'unhealthy' compared to these two people sharing a merry mo- 
ment. This refers to the issue of 'pairing' (Bion 1966), when subgroups in a larger group jeopardize the capacity of the group as a whole to work together constructively. I found his remark very important as it helped me to see how easily such 'pairing' happens and how important it is for the therapist and the interpreter to maintain an equal distance to the patient as well as to the interpreter/therapist. In the treatment of asylum seekers and refugees, issues of (alleged) political affiliation and trust are mentioned as problematic by both therapists and patients. This may not be very different from interpreter-mediated dialogue in the judicial system and in health care in general. In mental health care sessions, though, these feelings may have to be investigated: is mistrust an understandable and justified feeling in this context, or does it point to a therapeutic problem?

\section{Research into dialogue interpreting in mental health}

There is no lack of publications about dialogue interpreting in health care. The main topics that are dealt with are the professionalization of the field, role issues, and the quality of interaction and translation (Bot 2005). Some of the articles discuss matters that are also of interest to interpreting in mental health care. The nature of most of these publications, however, is problematic: they are highly impressionistic and reflect the sometimes all too personal experiences and opinions of the authors. This often leads to unwarranted statements and to different authors ventilating opposing views based on implicit criteria. Only recently (starting in the early 1990s and encouraged by the international Critical Link Conferences) have studies based on empirical data been published.

Recent empirical studies in dialogue interpreting point to a multi-faceted influence of the interpreter on the interaction between the primary speakers (Wadensjö 1998; Roy 2000; Bot 2005), and to the importance of several 'other factors' on the assessment of the quality of interpreting by its users (Gile 1995). Wadensjö (1998) states that interpreted communication is about the interaction between three parties: the interpreter and the people speaking the two languages involved. She states that "the meaning of what is said is settled in and by interaction between individuals" (1998: 279). I myself have emphasized the importance of the influence of the interpreter on the organization of the dialogue, in addition to his influence on the 'text' - i.e. the words that are being said. In short, interpreters are of necessity part of the interaction: they have an influence on the organization of the communication and on the text by negotiating meaning (Bot 2003, 2005). This is an intriguing point of view when considering interpreting in mental health. Therapists and patients also negotiate meaning, creating 'a therapeutic reality'. Combining this with Wadensjö's view would imply that in interpreter-mediated psychotherapy, the interpreter inevitably becomes part of the therapeutic reality.

It therefore seems useful to summarize some of the most pertinent research findings, which I have grouped together under the headings text 
(§ 3.1.), organization $(\S 3.2$.) and other factors ( $\$ 3.3$.) first, and then to relate their importance to the field of mental health care.

\subsection{Text}

An important aspect of interpreting is the equivalent rendition of the words of the primary speakers. Below, I summarize some research findings that provide insight into the problems that arise in such renditions and into the source of their divergence.

In Hamburg (Germany), a group of researchers investigated the involvement of ad hoc interpreters (i.e. family members, bilingual hospital personnel) in informed consent procedures (see Bührig 2002; Bührig \& Meyer 2004; Kroffke \& Meyer 2005). They concluded that the lack of knowledge of the institutional purpose of the communication led to translations that diverged from the original in important respects. For example, an important element of an informed consent dialogue is the doctor presenting a treatment procedure that he 'wants' or 'would like' to perform, informing the patient about its possible consequences and risks and asking his permission to do so. The research team in this case found that their interpreters had the tendency to change the modal verb 'want' into 'will' - thus presenting to the patient a doctor who had made a decision and was simply informing him about the treatment he was going to carry out. Bührig \& Meyer (2004: 7) write "that it is not language contrast or lack of linguistic proficiency that cause the change from 'want' to 'will', but rather a lack of awareness of such inconspicuous linguistic elements and their far-reaching institutional implications".

Kennard et al. (i.e. Roberts \& Elliott (2002) and Kennard, Elliott, Roberts \& Evans (2002) published two articles about group analytic sessions with interpreters. The groups were training groups in which the participants were professionals training to become specialists in group analytic psychotherapy. Both therapist and trainees reported that they felt that in general they understood each other. Misunderstandings could clearly be traced in the interactions as some of the participants were bilingual. Problems arose when the interpreter could not translate everything because more than one person was speaking at the same time, or because people spoke softly or too fast. Kennard et al. also investigated the therapeutic character of the sessions - did the groups have a psychoanalytic character - and they asked the group members to indicate which events during the sessions had been most important for them personally and why. The responses to this question turned out to be difficult to classify in therapeutic categories and the authors attributed this result to the fact that in the translation the words 'for you personally' had not been included.

The observations of the Hamburg team and of Kennard et al. relate closely to my own. In my analysis of videotaped therapeutic sessions with an interpreter, I decided to compare original turns and their renditions studying three aspects. Firstly, did the perspective of person remain un- 
changed (most often meaning: did the interpreter interpret in the first person?). Secondly: had all of the information, the content of the message, been rendered? And thirdly, had the therapeutic character of the turn been rendered? To define this therapeutic character I used a categorization system designed for use in psychotherapy research: if the original utterance and its rendition could be classified in the same category, the rendition was seen as 'equivalent' as far as this aspect was concerned. These three aspects together formed my 'equivalence concept' for mental health talk. One of the observations, applying this concept, was that interpreters often missed out the 'relational' aspects of the therapist's words in the rendition (Bot 2005). I attributed this to the interpreter's lack of knowledge of the relational character of psychotherapy. Therapy is not something the therapist can administer to the patient: it is something therapist and patient engage in together and that emerges in their therapeutic relationship. This resembles the omission of "for you personally" described by Kennard et al.: therapy is about a personal experience and not about 'objective' truth. I also found questions by the therapist enquiring about the patient's feelings, changed into statements. As a result, the dialogue changed from one in which the therapist tried to make the patient reflect on himself, into one with a therapist as an expert telling the patient how he felt.

Apart from problems of the type mentioned by Meyer et al., I also found changes that I attributed to the interpreter's (unconscious?) personal opinions about 'what is good behaviour', thus giving some credence to Yahyaoui's concerns mentioned above.

I found, for example, that sometimes explicit interventions by therapists stating that it would be healthy for a patient to talk about his problems, were changed into their very opposites: that it is better not to talk (as that is seen as more pleasant for people all around you). Englund-Dimitrova (1997) assumes that there is a decision component, a conscious choice, at work in divergence, and more specifically so in omissions made by interpreters.

The findings from these research projects clearly point to the interpreter's influence on the content of the communication in several ways. Apart from the language pair dependent changes there are changes that are dependent on the interpreter: his (lack of) knowledge of the type of communication in hand; his (lack of) knowledge of the institutional setting in which the communication takes place and the specific linguistic characteristics of that type of talk; his (un)conscious personal ideas, values and norms, all of which may make him diverge from the original text.

\subsection{Organization}

The most evident influence of the interpreter on the organization of the dialogue is obvious in the turn taking patterns: usually the interpreter has every second turn. It is generally assumed that the interpreter plays a role in the 
organization of the turn taking - as he is the one who understands what people are saying (e.g. Englund-Dimitrova 1997; Wadensjö 1998; Roy 200). I have shown that therapists are in a position to direct the turn taking to a large extent and that they do so using prosodic means, gestures and gaze (Bot 2005). However, as content and grammar are important elements in defining a turn transition place, the therapists will never be able to direct this fully. I noticed a relationship between the organizationof the turn transfer, the number of divergent renditions and the occurrence of serious misunderstanding. Especially overlapping speech and an interpreter who has to make an effort to get his turns in, go together with a large number of divergent renditions. This points to an inherent problem of interpreter-mediated talk: it is important that the therapist organizes the turn transfer quite strictly in order to diminish the risk of divergence and to remain in control of the session; but at the same time, he has only limited means to do so as he lacks insight into the content of what is being said.

In psychotherapy, therapists would sometimes like patients to 'unburden' themselves: when they speak about traumatic events, they should not be interrupted as this may stop the therapeutically important flow of speech. This leads to a dilemma in interpreted therapy. The longer the turn, the greater the risk that the rendition will be divergent. What becomes more important then: equivalent renditions or an uninterrupted flow of talk? I have noticed in my research that divergent renditions can lead to complications which leave the patient misunderstood by the therapist, a situation which is unpleasant and must be avoided. Therefore, obviously, equivalent renditions are more important: a patient interrupted is better than a patient misunderstood. As this is an important aspect of therapy with traumatized patients, it is worthwhile to investigate this tension between accuracy and flow further.

\subsection{Other factors}

Various articles mention factors that can have an influence on the quality of the communication but that cannot be easily categorized under the heading of 'text' or 'organization'.

Gile, for example, mentions the quality of the interpreter's linguistic output (i.e. the target 'text'), the quality of his voice, the prosodic characteristics of his delivery, the quality of his usage of terminology, as factors influencing users' assessment of quality (Gile 1995: 151). Cheung (2003) shows the importance of the accent of the interpreter in the assessment of the quality of his work by users. But even though these factors play a role in the assessment of the interpreter's work, it is unclear to what extent or how they influence the process of the dialogue.

Wadensjö (2001) mentions that the seating arrangement, the placement of the interpreter vis-à-vis therapist and patient, influences the patient's feeling of security, his willingness to talk about difficult issues and 
the quality of the dialogue. She indicates the importance of the inclusion of all participants in one "communicative radius".

There are some publications that pay specific attention to the psychotherapeutic concepts of transference and countertransference and the issue of resistance in interpreter-mediated talk and how this influences the development of the therapy. Haenel (2001) suggests that (counter)transference feelings between patients and interpreters do occur. It is unclear whether he interviewed interpreters and patients about these feelings or whether he merely relies on his own observations.

Kennard et al. make some mention of the feelings of their interpreters (shock because of obscene language or intense emotions) but there is no mention as to how these feelings influence their functioning as interpreters, nor do they report how the presence of interpreters is experienced by the group members. None of the authors pays attention to how language issues and the presence of the interpreters are used to strengthen or weaken resistances. It seems plausible that in groups, group members may purposefully speak softly or too fast to make their words untranslatable.

In the Netherlands it has become standard practice to work with interpreters via the telephone, also in psychotherapy sessions lasting an hour or even longer, as well as in meetings with couples and families. Apart from Wadensjö's article about telephone interpreting in police interrogations (1999), we have no systematic insight into this type of talk. Wadensjö concludes that there is not so much a difference in content as a difference in the fluency of the story told by the interrogated person when one compares an on-site interpreted event with three participants and the same three participants in a telephone interpreted event.

In my own research (Bot 2005), I have found that the general attitude of the health provider vis-à-vis interpreter-mediated dialogue - I called these "models of cooperation" - influences the proceedings of the session. One therapist who saw the interpreter as a 'translation machine', turned out to make no allowance for the correction of divergent renditions. He made no use of repair mechanisms such as recycled questioning and rapid turn change to allow for feedback. Therapists who started from the view that interpreting is an interactive activity, used these repair mechanisms and this helped to prevent misunderstandings.

\subsection{Where do we stand?}

I have shown that interpreting in mental health care is different in several ways from interpreting in other settings. But we have as yet only a very limited insight into what these differences exactly are and how they (should) influence the practice of interpreting in mental health dialogue.

The empirical research in this field that I have referred to in this article is essentially qualitative in nature, based on a limited corpus and methodologically not very strong, and I emphatically include my own research project in this assessment. I analysed six hours of video-taped sessions. The 
foreign language turns were translated and checked by native speakers of those languages, but I had to take these translations at face value and did not engage in any sociolinguistic investigation in order to grasp the (differences in) meaning on a deeper level. I designed an "equivalence concept", which I used to compare original primary turns and their renditions Although I defined equivalence or divergence of the renditions with the help of this equivalence instrument, I did so single-handedly. I noticed that sometimes original-rendition pairs diverged on aspects that were not included in my concept - these divergences were therefore not included in the analysis. I have taken this as an indication of the complexity of the matter but at the same time it also shows how 'soft' the results are.

Wadensjö's (2001) conclusion on the importance of a shared "communicative radius" is based on two video-taped sessions only, each session with the same doctor and patient, but with different interpreters. Although it is no doubt possible that the seating arrangement, with its concomitant effects on the exchange of gaze, contributes to the ease with which the patient tells his story, Wadensjö also mentions other differences between the two sessions that could also contribute to a better outcome of the therapy session: patient and doctor are better acquainted in the 'better' session and they are used to being video-recorded; and there is the factor of a male versus a female interpreter each with different working styles. We may therefore conclude that all these factors might have played a role in making it easier for the patient to talk but we have as yet no means of assessing the weight of these different factors separately.

So although several research projects systematically analyse empirical data and constitute serious efforts to come to an understanding of the field, they focus on limited aspects of the interaction and they do not offer much more than indications of problem areas and of how these problems manifest themselves. Research has been focused on describing 'what happens'. Some authors do give guidelines about how interpreters should work, but these not rely on systematic research and there is no consensus among practitioners and interpreters.

Another problem concerns the level of professionalization of the interpreters. The Hamburg team investigated the performance of non-professional interpreters, concluding that the participation of these interpreters deepens the communicative asymmetries that are inherent to doctor-patient discourse (Bührig \& Meyer 2004). They add that it is uncertain how socalled professional interpreters would perform under the same conditions. I have shown that my 'professional' interpreters (interpreting being their profession) indeed diverge from the original turns in ways that are similar to their non-professionals' approaches. I also showed that in the sessions I analysed, serious misunderstandings occurred despite the involvement of an interpreter. This leads to two more important points of attention.

First, the illusion exists that because an interpreter is present, there are no communicative problems. This indicates the importance of training not only the interpreters but also the users of interpreting services in what they can realistically expect from interpreters. 
Second, how 'professional' are professional interpreters? Professionalism is defined mainly in organizational terms while the development and implementation of standards of linguistic and interpreting proficiency in all its subtleties and of attitudinal aspects is still in its infancy.

\section{Suggestions for further research}

Pöchhacker (2004) distinguishes seven conceptual levels that can be foregrounded in the representation of 'interpreting': anthropological, socio-professional, institutional, interactional, textual, cognitive and neural. He describes this sequence as "extending from the 'outer' spheres of social context to a neuro-cognitive core, or, more pointedly, from socio-cultures to synapses" (Pöchhacker 2004: 86). The three levels situated in the middle of this model are most interesting for research that focuses on interpreting in mental health. These are:

- the institutional level: focusing on the functioning of interpreters and interpreting in (certain types of) institutions;

- the interactional level: foregrounding the interactional character of interpreting as an activity;

- the textual level: focusing on interpreting as a discursive and textual process.

\subsection{Institutional}

First of all, every "catchment area" (countries, large urban areas) needs quantitative data about the need for language assistance in mental health care. Moreover, it is necessary to distinguish between different types of dialogue within mental health care: the professional status of the health provider (for example: social worker; psychiatric nurse, psychologist, psychiatrist) and the type of session (for example: intake session, psychiatric diagnostic interview, insight oriented psychotherapy, medication consultation). Furthermore, we need to know the strategies mental health providers use to cope with patients with limited or no language skills in the lingua franca. Do they make use of interpreters, do they ask bilingual staff or family members, or use a contact language or gestures to solve the problem?

In addition to these basic data, it is worthwhile to know from which model health providers are working: do they see the interpreter as a translation-machine or do they work from an interactive stance towards interpreting? What role do they ascribe to the interpreter? Is this situation and context-dependent? One should also investigate the specific problems (and benefits) therapists and interpreters experience in their work together, and for interpreters - the stress factors specific to working in the field of mental health. 
One aspect that is generally underestimated in (mental) health research is the patients' perspective. Their views should be included in the investigation and they should be asked about whether their preferences and expectations, as far as the involvement of an interpreter is concerned, have been respected. They should be questioned about their experience of being understood or not ${ }_{2}$ and about their views on communication during the session overall.

There is some work which can be used as a base to build on: e.g. the work of Hertog \& Van Gucht (2003) focusing on quantitative data concerning the occurrence of language problems and the way these are being solved in Belgian general hospitals; my own research as far as it focuses on models of cooperation and problems encountered during sessions (Bot 2003, 2005); and the work of Baistow (2000) on stress in community interpreting.

\subsection{Interactional / textual}

There are two reasons why the interactional versus textual levels Pöchhacker distinguished might be combined into one. Firstly, because these two aspects of discourse are closely interconnected (see Wadensjö 1998 and Bot 2005) and, secondly, because for both levels we need to investigate audio and/or video-taped interpreted dialogue.

The work on the institutional level provides a base to build on: at least we now know the scope of the phenomenon. To find out what happens in the interaction itself, between the participants in talk, the interaction has to be analysed in close detail. I do not think that we will be able to design simulations and experiments in the near future which can imitate some of the basic characteristics of interpreter-mediated mental health talk. For the time being, we have to rely on ecological validity and investigate interpreter-mediated talk in its natural habitat: the consulting room. To overcome these methodological problems, it will therefore be helpful to establish close(r) connections with psychotherapy research.

With these remarks in mind, I would like to suggest the following priorities.

1. In-depth research into the processes at work in interpreter-mediated mental health care. This could include the following:

- Sociolinguistic research: focusing on the comparison between original turns and their renditions. As this type of research is language-pair specific, research focusing on a specific language pair could serve as a first investigation to come to grips with this very problematic aspect of interpreter-mediated mental health treatment;

- An investigation into the influence and impact of the interpreter/interpreters on the development of (counter)transference and resistance; 
- Investigations focusing on 'special situations' in which the role of the interpreter is especially challenging; for example, in the psychiatric diagnostic interview; in crisis interventions or in sessions with families involving children.

This would require several methodologies. Some questions could be explored with the survey-method but often the analysis of videotapes and transcripts would be needed, while a longitudinal set up - following the treatment of a patient over some period of time - could also provide much needed information about the course of the treatment with interpreters.

2. Telephone interpreting: this medium has become the standard in the Netherlands in (mental) health care. Systematic investigation into what happens in this type of talk in mental health care is non-existent. How are the sessions, especially the turn taking, organized? Is the quality of the renditions influenced by the medium; how do the participants cope with the absence of non-verbal exchange between interpreter and primary speakers? How does it influence the feelings of security of the primary speakers? And another important aspect: how does it influence the working conditions of the interpreters?

3. In addition to these priorities, it is also necessary to analyse cases of noninterpreted dialogues with patients with language problems in (mental) health care. Are the standards for adequate health care met in these situations? In what ways are these sessions different from interpreter-mediated dialogues? Can we keep up the belief that interpreted sessions are 'better' and how can we define what is 'good'?

4. Several research results point to the importance of interpreters being trained (better) to perform better in mental health talk, and in several places training programmes have been set up. These programmes focus on raising the level of knowledge about mental health care and the way mental health dialogue is shaped, based on the assumption that this knowledge helps to improve the interpreter's performance (i.e. both in attitude and in the production of equivalent renditions). However, there is a need to evaluate these programmes: do they indeed improve the quality of the interaction and in what way?

\section{Conclusion}

Although I did not include the anthropological and socio-professional levels in my survey of potential and necessary research, what happens on those levels, of course, also influences the research activities that I suggested above.

Politically, the issue of interpreting in the public sector is becoming an increasingly difficult one. In the EU xenophobia is on the rise and this 
has become associated with the demand that immigrants should learn the language of their host countries as soon as possible. However, this obviously does not solve the problem that health providers face in their consulting rooms. In Belgium an estimated $25 \%$ of the patients in general hospitals in the big cities need some kind of language-assistance (Hertog \& Van Gucht 2003). However, in the current political climate the willingness of the public services to invest in interpreting services is clearly diminishing as is the willingness of health insurers to fund them, and of health providers to deal with this issue properly. In this respect I have been very happy with the stance taken by the Dutch Ministry of Health, mentioned above in section 1.

All the same, there are also other problems hampering research in interpreting. Process research - i.e. research into what happens within the spatio-temporal confines of the session - is a methodologically complicated area of research, requiring intensive contacts and exchanges with psychotherapy research and conversation analysis, along with research into interpreting all over the world. The fact that so many languages are involved and the very different levels of professionalization of the various interpreters working in these languages, complicate the research projects even further. Research would probably be easier if a research team consisted of researchers who are fluent in the languages they investigate - but this is not easy to set up either. Another problem is that interpreting is usually not taught at university level, which explains why there are so few people who have a 'natural' interest in this type of research.

Therefore, we have to work on creating an interest in people from different backgrounds - social scientists, linguists, interpreters, communication specialists - to engage in interpreting research. In our case, when conducting research on interpreting in mental health care, mental health specialists should be included in the team.

A strong argument in favour of using interpreters and continuing with interpreting research in mental health care is that problems in the interaction between people from different countries are usually first and foremost language problems. Helping foreigners, immigrants or newcomers to integrate in their new countries, starts with a committed effort and the mere possibility to understand each other. Only when the language problem has been solved, can participants in talk find out where and how they are different and come to the conclusion that they also have in fact a lot in common.

Professional interpreting services as well as training for the providers and users of interpreting services, enlightening them about the ins and outs of the profession, are prerequisites for any modern international society. 


\section{Bibliography}

B \& A Groep (2005). Het Toetsingsproces getoetst, evaluatie van het kwaliteitstraject tolken en vertalers van het Ministerie van Justitie. The Hague: B \& A Groep.

Baistow, Karen (2000). Dealing with other people's tragedies: the psychological and emotional impact of community interpreting. London: Brunel University.

Bion, Wilfred R. (1961). Experiences in groups. London: Tavistock.

Bot, Hanneke (2003). Tolken in de Geestelijke Gezondheidszorg, een specialisme apart? Rapportage voor WODC. The Hague: Ministerie van Justitie.

Bot, Hanneke (2005). Dialogue Interpreting in Mental Health. Amsterdam \& New York: Rodopi Publishers

Bührig, Kristin (2002). "Multimodalität' in gedolmetschten Aufklärungsgesprächen, Graphische Abbildungen in der Wissensvermittlung". Arbeiten zur Mehrsprachigkeit Folge B, Series $B$ 39. University of Hamburg.

Bührig, Kristin \& Bernd Meyer (2004). "Ad-hoc interpreting and the achievement of communicative purposes in specific kinds of doctor-patient discourse". Arbeiten zur Mehrsprachigkeit Folge B, Series B 57. University of Hamburg.

Cheung, Andrew (2003). "Does accent matter? The impact of accent in simultaneous interpretation into Mandarin and Cantonese on perceived performance quality and listener satisfaction level”. Collados Aís, Manuela Fernándes Sánchez \& Daniel Gile (eds). La Evaluación de la Calidad en Interpretación: Investigación. Granada: Editorial Comares, 85- 96.

Englund-Dimitrova, Birgitta (1997). "Degree of Interpreter responsibility in the Interaction Process in Community Interpreting". Silvana Carr, Roda Roberts, Aideen Dufour \& Dini Steyn (eds). The Critical Link: interpreting in the Community 2. Amsterdam: John Benjamins, 147-164.

Gile, Daniel (1995). "Fidelity Assessment in Consecutive Interpretation: An Experiment". Target $7(1): 151-164$.

Haenel, Ferdinand (2001). "Ausgewählte Aspekte und Probleme in der Psychotherapie mit Folteropfern unter Beteiligung von Dolmetschern". Verwey, M. (ed.). Trauma und Ressourcen / Trauma and Empowerment. Berlin: VZW Verlag, 307-315.

Hertog, Erik \& Jan van Gucht (2003). "Onderzoeksopdracht: Taalbijstandsbehoeften in de Belgische algemene ziekenhuizen”. Antwerp: Lessius Hogeschool.

Kennard, David, Jeff Roberts \& Barbara Elliott (2002). Group Analytic training through a Language Interpreter: are we understanding each other? Group Analysis, the Journal of Group Analytic Psychotherapy 35(2), 209 - 235.

Kennard, David, Barbara Elliott, Jeff Roberts \& Chris Evans (2002) "Group Analytic training Conducted through a Language Interpreter: is the experience therapeutic? Is it group Analytic?" Group Analysis, the Journal of Group Analytic Psychotherapy 35(2), 237 - 250.

Kroffke, Solveig \& Bernd Meyer (2005). "Verständigungsprobleme in bilingualen Anamnesegesprächen". Arbeiten zur Mehrsprachigkeit Folge B, Series B 61. University of Hamburg.

Pöchhacker, Franz (2004). Introducing Interpreting Studies. London/New York: Routledge.

Roy, Cynthia (2000). Interpreting as a Discourse Process. New York/Oxford: Oxford University Press.

Wadensjö, Cecilia (1998). Interpreting as Interaction. London / New York: Longman

Wadensjö, Cecilia (1999). "Telephone Interpreting and the Synchronisation of Talk". The Translator 5(2), 247-264.

Wadensjö, Cecilia (2001). "Interpreting in Crisis, the interpreter's position in therapeutic encounters". Mason, Ian (ed.). Triadic Exchanges, Studies in Dialogue Interpreting. Manchester UK/Northampton MA: St.Jerome Publishing, 71-85.

Yahyaoui, Abdessalem. (1988). "Consultation familiale ethnopsychanalitique: le cadre intercultural". Troubles du Langage et de la Filiation. Grenoble: Editions La Pensée Sauvage, 49-67.

\footnotetext{
1 'He', 'his' and 'him' are used generically in this article to refer to persons of either sex.

2 In Dutch: de "Wet op de Geneeskundige Behandelovereenkomst" (WGBO, 1995).

3 In the Netherlands the Ministry of Justice has been responsible for all interpreter services in the public sector, including health care. Only recently, is this being changed.

${ }^{4}$ Kernteam Kwaliteitsnormering Tolken en Vertalers (Committee on Quality Norms Interpreters and Translators).
} 


\begin{abstract}
${ }^{5}$ At present I'm preparing such training, with the help of the Pharos Foundation, an advice centre for the health care for refugees, and Phoenix, an expertise centre for transcultural psychiatry.

${ }^{6}$ There is one exception: mental health institutions specialised in the care for hearing impaired people employ sign language interpreters. Obviously this is possible because all their patients need language assistance in the same language. Health care institutions dealing with foreign patients have to cover a multitude of languages.

7 Psychotherapists have to undergo training-therapy as part of their schooling in order to improve their self-knowledge. This should enable them to distinguish their own psychology from that of the patient.
\end{abstract}

